\title{
BIOPOLÍTICA E ESCOLA MODERNA: APONTAMENTOS PARA UM DEBATE
}

\author{
Marcelo Rito ${ }^{1}$ \\ Julio Groppa Aquino ${ }^{2}$
}

\section{RESUMO:}

O presente artigo dedica-se a contribuir para o debate acerca dos estudos foucaultianos na educação realizados no Brasil atualmente, por meio da proposição de um plano investigativo voltado à díade biopolítica-escolarização, sobretudo no que diz respeito à implementação da pedagogia moderna no país nas décadas de 1920/30, cujos ecos parecem persistir na atualidade educacional. Para tanto, são retomadas as teses principais da teorização de Michel Foucault acerca da "estatização do biológico" e da emergência da população como problema político, por meio da ascensão de procedimentos públicos voltados à regulamentação dos contingentes populacionais em seu conjunto sem a necessidade de estabelecer novas instituições de sequestro, tal como ocorrera na era disciplinar. Em seguida, são revisitados criticamente alguns estudos de cunho historiográfico que se valeram de tal referencial para entabular suas análises, os quais parecem ter se confinado em um tipo de interpretação da biopolítica no campo educacional como imposição, ressignificação ou mero disciplinamento das populações escolares. Daí a escola moderna ser tomada amiúde como tributária de um amplo programa ideológico dedicado a desviar os cidadãos e, mais especificamente, os escolares de uma suposta origem livre, igualitária e autêntica. Ao final das discussões, são apresentadas algumas digressões acerca das possibilidades analíticas oferecidas pelos últimos cursos ministrados por Foucault, por meio das quais talvez se lograsse ultrapassar o binarismo poder/resistência, alcançando o cerne dos processos de veridicção/subjetivação que levam os indivíduos modernos a se conceberem como seres em permanente desenvolvimento, em busca de constante segurança e autocontrole perante um mundo de infinitos estímulos para corpos tidos como limitados, mas plenamente adaptáveis.

Palavras-chaves: biopolítica; educação; escolanovismo; Michel Foucault.

\section{BIOPOLITICS AND MODERN SCHOOL: NOTES FOR A DEBATE}

\begin{abstract}
:
This paper aims at contributing to the debate about the current Foucauldian studies in education in Brazil, by proposing a research agenda focused on the dyad biopolitics-schooling, especially with regard to the implementation of modern pedagogy in the country in the decades of 1920/30, which seems to reverberate in the educational present. For this purpose, we take up the main propositions of Michel Foucault's theorizing about the "statization of the biological" and the emergence of the population as a political problem, made possible by the rise of public procedures devoted to regulating population contingents as a whole without the need to arise new institutions, as it occurred in the disciplinary era. Then, we review critically some historiographical studies that have used such a framework to develop their analyzes, which seem to have been restricted to a kind of interpretation of biopolitics in the educational field as imposition, resignification or mere discipline of school populations. Hence modern school is often related to a broad ideological program dedicated to diverting citizens, and more specifically, school children from an allegedly free, egalitarian and authentic nature. In the final discussions, we present some digressions on the analytical possibilities offered by Foucault's last courses, by means of which one could overcome the binary pair power/resistance, reaching the core of the veridiction/subjectivation processes that lead modern individuals to conceive themselves as beings in permanent development, in search of constant security and self-control towards a world full of stimuli for bodies considered as limited but completely adaptable.
\end{abstract}

Key words: biopolitics; education; New School Movement; Michel Foucault.

Em 8 de Janeiro de 1975, Michel Foucault iniciou um ciclo de aulas no Collège de France, intitulado Os anormais, cujo tema central abrigava o desejo de sondar aquilo

\footnotetext{
${ }^{1}$ Doutor em Educação pela Faculdade de Educação da USP. E-mail: ritomarcelo@gmail.com.

${ }^{2}$ Professor Titular da Faculdade de Educação da USP. E-mail: groppaq@usp.br.
} 
que ele sugeriu como "a emergência do poder de normalização" (Foucault, 2001, p. 32). Para tanto, o pensador compilou referências díspares, tais como tratados de medicina legal do século XIX, regulamentos de instituições de internamento no século XVII, estudos dirigidos à cruzada antimasturbatória do século XVIII, clássicos da psiquiatria eugenista do XIX, dentre outras.

Por meio de tal itinerário investigativo, o referido pensador pôs em evidência algo que ficou consagrado em sua obra como o despontar do poder disciplinar. Considerando a produção foucaultiana atinente à segunda metade da década de 1970 (Foucault, 1987; 2001; 2005), pode-se deduzir que a normalização surge como efeito de práticas dirigidas a indivíduos submetidos a uma gama de procedimentos disciplinares aplicados, por sua vez, por uma gama de instituições de sequestro; estas fundadas, mormente, na passagem do século XVIII para o século XIX.

Analisando os discursos compilados por Foucault em Os anormais, depreendese que o referido processo de normalização teria sido possibilitado, dentre outras intercorrências históricas, pelo advento e pela posterior generalização do exame psiquiátrico. Essa prática teria levado à definitiva submissão do saber psíquico à lógica médica. Por meio dela, ter-se-ia constituído um olhar que ultrapassava a superfície da anatomia delinquente, imergindo nos mecanismos psíquicos que redundavam em determinado comportamento inadequado. Tal perspectiva permitiu produzir especulações que supunham o sistema nervoso como o locus onde se processava a estimulação externa e, por conseguinte, se estabeleciam condutas anormais.

$\mathrm{Na}$ esteira de tal lógica, a psique foi consagrada como o centro sensível onde se desenvolviam as patologias sociais. Tal mecanismo torna-se visível quando Foucault analisa a chamada cruzada antimasturbatória procedida pela Igreja Católica no século XVIII em seus internatos e paróquias, a partir da qual teria despontado um tipo de discurso que visava situar uma causa geral - ao mesmo tempo, pessoal e social considerada própria a todas as doenças psíquicas, qual seja, o corpo erotizado do infante.

Esse corpo que antes da psiquiatrização da sociabilidade irrompia em processos patológicos, passaria a ser considerado, após a segunda metade do século XIX, depositário de um estado permanente no qual se desenvolveria ou se preveniria o desabrochar da doença mental.

\begin{tabular}{|l|l|l|l|l|}
\hline Qovista Oialectus & Ano 4 & n. 11 & Agosto - Dezembro 2017 & p. $127-144$ \\
\hline
\end{tabular}


A partir das enunciações foucaultianas, pode-se aventar que quando os psiquiatras ainda procuravam a origem das patologias em estigmas presentes nos indivíduos, eles associavam as enfermidades mentais a supostas deformações do funcionamento psíquico. Porém, quando tais especialistas passaram a mirar o ambiente em que se encenava a loucura, as causas para as irrupções doentias passaram a ser vasculhadas em outra instância da vida dos acometidos: a infância.

A concepção segundo a qual a loucura passaria a ser explicada a partir da vida imberbe do insano ganhou força durante o desenrolar do século XIX. Isso levou Foucault (2001, p. 387) a asseverar que "a infância foi o princípio de generalização da psiquiatria”. Assim, ao buscar resquícios de infância no comportamento anormal, os psiquiatras pós-1850 teriam tratado as patologias mentais como interrupções no desenvolvimento do indivíduo afetado, comparando-o com o grupo social a que ele pertencia.

Desse modo, nas palavras de Foucault, foi "revirando cada vez mais profundamente a infância, que a psiquiatria pôde se tornar a espécie de controle geral das condutas, o juiz titular, se vocês quiserem, dos comportamentos em geral" (Foucault, 2001, p. 392). Desse modo, a psiquiatria adquiriu o status de saber normativo dedicado a converter excentricidades em anomalias. Por meio da medicalização do normal, esse saber teria estabelecido, portanto, a anormalidade como fator incurável, atribuindo à psiquiatria o papel de "ciência da proteção biológica da espécie" (Foucault, 2001, p. 402).

As explicações psiquiátricas para a anormalidade potencializaram sua força de verdade quando o componente genético foi introduzido nos diagnósticos. A entrada do “corpo dos pais" (Foucault, 2001, p. 399) nas justificativas para as doenças mentais teria atrelado, definitivamente, cada qual dos indivíduos à crença no vínculo indissolúvel entre mente e comportamento. Tal associação seria responsável pela aparição da noção de estado psíquico, cuja definição incorporava a crença em um fundo causal comum às capacidades e incapacidades de cada qual dos indivíduos.

Partindo desses pressupostos, Foucault sustentou que a mirada biológica para os comportamentos, muito além de os determinar, permitiu que as ciências modernas dirigidas à vida se arrogassem a condição de defensoras da sociedade, na medida em que se responsabilizaram por consertar, extirpar e, acima de tudo, prevenir fatores que interrompessem ou desviassem o fluxo vital saudável nas populações por elas alvejadas.

\begin{tabular}{|l|l|l|l|l|}
\hline Gonista Dialectus & Ano 4 & n. 11 & Agosto - Dezembro 2017 & p. $127-144$ \\
\hline
\end{tabular}


O curso que se seguiu ao projeto desenvolvido na obra Os anormais foi aquele nomeado Em defesa da sociedade. Os leitores que esperavam o complemento do projeto apresentado em 1974-1975, frustraram-se. Foucault, que em Os anormais analisara a emergência do monstro psiquiátrico e do jovem onanista, não procedeu à descrição de um suposto infante indócil ao sistema escolar, tal como prometera no referido curso. $\mathrm{Na}$ obra Em defesa da sociedade, o pensador encaminhou sua genealogia do poder normativo em outra direção.

Deslocando o objeto de pesquisa anterior - das instituições psiquiátricas e educacionais para a história e a economia política europeias -, Foucault passou a tratar das diferentes hipóteses acerca do exercício do poder político no pensamento ocidental a partir de filósofos, historiadores e políticos atuantes nos séculos XVII, XVIII e XIX. Dessas conjecturas, destacou o embate de duas concepções que o auxiliaram a aprofundar as análises em torno da normalização: a de que o poder é tomado meramente em termos de repressão/resistência e aquela segundo a qual ele se afirma como jogo de forças.

Optando por adotar a concepção nietzschiana, Foucault contestou as hipóteses repressivas do poder tal como eram formuladas por autores como Wilhelm Reich. Para o pensador francês, dever-se-ia compreender o exercício de poder como um campo intrinsecamente dependente da produção de verdades. Estas, muito além de esconderem equívocos ou mesmo desviarem os sentidos das condutas, deveriam ser analisadas como produtoras de sentidos compartilhados socialmente, sendo empregadas por segmentos sociais tão díspares como intelectuais, juristas, cientistas, militares ou políticos.

A partir dessa compreensão, no curso de 1976, Foucault promoveu um giro empírico de suas investigações. O objeto passou então a contemplar obras pertencentes à filosofia iluminista, à ciência política contratualista e à história medieval, produzidas entre os séculos XVII e XIX. A partir desse grande apanhado, o autor sugeriu que a guerra ter-se-ia tornado o gabarito para a inteligibilidade dos enunciados voltados à justiça, à revolução e ao gerenciamento do Estado.

Com base nessa suposição, o pensador francês especulou que o epicentro dos discursos pronunciados logo antes e muito depois da Revolução Francesa poderia ser localizado na guerra das raças.

Desse modo, segundo Foucault, teria surgido no pensamento ocidental a crença segundo a qual a raiz primária de todo o edifício jurídico, regulamentador e bélico

\begin{tabular}{|l|l|l|l|l|}
\hline Gonista Dialectus & Ano 4 & n. 11 & Agosto - Dezembro 2017 & p. $127-144$ \\
\hline
\end{tabular}


moderno estaria fundada em um grande estado de armistício, no qual cada grupo social deveria reconhecer a conjuntura de perigo constante frente à ameaça de novas derrotas ou ao retorno dos inimigos banidos.

Foucault, no desfecho do seu curso de 1976, assevera que a sociedade de segurança, patente nas práticas discursivas dirigidas ao entorno social pós-século XIX, englobou, para além de procedimentos estatais, os discursos científicos. Conforme essas análises, a modernidade teria entronado uma lógica segundo a qual o medo do perigo externo orientaria a busca do fortalecimento interno dos grupos sociais imersos nos saberes sociológicos, médicos e jurídicos instituídos após a vitória do Estado de direito contra o Absolutismo.

A última aula do referido curso, ministrada em 17 de março de 1976, foi consagrada a retomar as considerações realizadas nas pregressas pesquisas acerca do poder normativo e a compreendê-las a partir da hipótese da guerra das raças.

Ao fazê-lo, o autor argumenta que a guerra concebida como gabarito de inteligibilidade dos processos históricos, desenvolvida pelos historiadores do século XVIII, deslocou-se, nos tempos da Revolução Francesa, para o tema da universalidade nacional, cuja coesão o Estado, agora constituído como um corpo de direitos, deveria manter.

Sugere Foucault que, para efetivar dita manutenção, os Estados pósnapoleônicos voltaram suas preocupações para o risco de degeneração que as populações sob sua guarda sofriam. Datam dessa época medidas voltadas àquilo que Foucault enunciou como "estatização do biológico" (Foucault, 2005, p. 286). Por meio dessa conversão, tal coesão, que nos tempos revolucionários seria garantida por meio da igualdade em direitos, permitiria doravante a generalização de ações estatais dirigidas ao corpo, tanto individual quanto social, da população sob sua responsabilidade.

Despontaria, desta feita, aquilo que Foucault apresentou como a emergência da população como problema. Para sustentar dita perspectiva, o pensador descreveu a ascensão de procedimentos públicos voltados à regulamentação dos contingentes populacionais em seu conjunto, a céu aberto, sem a necessidade de estabelecer novas instituições de sequestro, tal como ocorrera no despontar da era disciplinar (meados do século XVIII). Nesse movimento, ganharam força os discursos dirigidos a processos vitais dos grupos humanos tomados em seu conjunto. Taxas de morbidade, índices de natalidade, condições de saneamento, modelos de previdência etc. começam a povoar as

\begin{tabular}{|l|l|l|l|l|}
\hline Gonista Dialectus & Ano 4 & n. 11 & Agosto - Dezembro 2017 & p. $127-144$ \\
\hline
\end{tabular}


preocupações tanto de técnicos quanto de políticos preocupados com os fluxos interno e externo das populações.

Destarte, por dentro, mas também por fora do Estado, começaram a proliferar enunciados de especialistas dedicados a aperfeiçoar a vida contida nos agrupamentos por eles pesquisados. Alavancaram-se então as teorias acerca do fortalecimento da energia vital, da maximização da produtividade e da minimização dos elementos mórbidos que assombravam os coletivos populacionais.

Foucault, a partir desses elementos, especula que, nesse ambiente, revigoraramse os enunciados dirigidos à raça; porém, não somente nos termos da medieval guerra das raças, mas em nome da garantia da saúde dos corpos inseridos nas populações passíveis à gestão estatal. Elevar-se-iam, desse modo, conjuntos de iniciativas organizadas segundo duas direções: tratava-se primeiramente de eliminar o perigo da contaminação de um grupo populacional por agentes externos; em segundo lugar, manter esse grupo sob vigilância contra os perigos internos que poderiam diminuir seu potencial de vida.

Essa vigilância operaria, segundo Foucault, por meio de numerosos agentes. Dentre eles, ganharam destaque aqueles dedicados à medicina. Sob a batuta dos discursos médicos, grandes populações administradas pelos Estados modernos teriam incorporado, em seus hábitos e léxicos, normas baseadas em certa convicção na salubridade. Mediante evocações dirigidas ao bem-estar, à longevidade e à produtividade, a busca pela fortaleza biológica ter-se-ia convertido no sumo projeto dos elementos que circulavam no interior de corpos pertencentes a dadas populações. Segundo essa lógica, quando cada indivíduo se dedicasse a proteger sua própria vida, ele assumiria, concomitantemente, a responsabilidade por garantir a perenidade da espécie biológica na qual estava inserido. Daí que obedecer, defender e fazer propagar as normas coletivas seria indispensável para que os elementos das populações garantissem tanto o desenvolvimento de suas vidas quanto a própria vitalidade da espécie.

Segundo Foucault, em paralelo ao poder disciplinar, que se escorava em normas dirigidas à organização de corpos individuais abrigados em instituições de sequestro, instituiu-se um poder alicerçado em uma normatividade difusa, voltada à expansão dos processos regulatórios da vida. Assim, responsabilização, compartilhamento e aprimoramento passaram a ser atitudes desejáveis a todos aqueles que viviam sob a

\begin{tabular}{|l|l|l|l|l|}
\hline Qovista Oialectus & Ano 4 & n. 11 & Agosto - Dezembro 2017 & p. $127-144$ \\
\hline
\end{tabular}


gestão biopolítica dos modos e estilos de existência. Portanto, segundo essa concepção, as relações de poder não poderiam ser consideradas apenas como algo que se produziria em um determinado campo de saberes e que se generalizaria para os demais grupos sociais. Doravante, os jogos veridictivos em torno do poder biológico - nas palavras do autor, biopolítico, precisamente - dependeriam da participação ativa dos indivíduos subjetivados no interior de tais relações.

\section{O lugar estratégico das práticas educacionais no horizonte biopolítico}

Gerir a própria vida, considerando-a um organismo biologicamente definido, geneticamente programado e higienicamente preservável, foi o escopo subjetivo a que se devotaram os indivíduos modernos, desde que se generalizaram as práticas de medicalização das populações nas cidades modernas no momento de intensificação do processo industrial. Além disso, a grande força de persuasão dos discursos de fundamentação biológica permitiu que eles se espraiassem nas mais variadas práticas sociais, principalmente em virtude de seu compromisso com a cientificidade das alocuções aí em circulação.

Entre tais práticas, a uma delas Foucault deu pouca atenção: a pedagogia. No entanto, apesar da escassez dessa tematização na teorização foucaultiana nos anos 1970, muitos autores dedicaram-se a estudar a história da educação à luz das conceituações acerca da disciplina e da biopolítica. No caso brasileiro, destaca-se José Gonçalves Gondra.

Na obra Artes de civilizar (Gondra, 2004), o autor debruça-se sobre as teses submetidas à Academia Imperial de Medicina e à Faculdade de Medicina do Rio de Janeiro para obtenção do credenciamento e da autorização para o exercício oficial da medicina no Brasil. Dedicando suas análises aos anos de 1850 a 1890, Gondra dissertou sobre dois elementos fundamentais para o estabelecimento da ordem médica no país. No primeiro caso, tratou-se dos esforços empreendidos para a institucionalização da medicina no território nacional; no segundo, dos aconselhamentos que o campo médico brasileiro reservou à escolarização.

No que tange ao primeiro aspecto, Gondra estabeleceu como marco o ano de 1808, quando, em razão da chegada da Família Real no Rio de Janeiro, a capital estabeleceu regras de funcionamento urbano a fim de garantir o saneamento e a higiene necessários ao ingresso do país no mundo civilizado. Nessa direção, o autor deixa claro

\begin{tabular}{|l|l|l|l|l|}
\hline Gonista Dialectus & Ano 4 & n. 11 & Agosto - Dezembro 2017 & p. $127-144$ \\
\hline
\end{tabular}


como se intercambiaram as práticas civilizatórias com as alocuções científicas. Aqui, a suposição do caráter social das doenças, assim como na Europa descrita pela pesquisa foucaultiana acerca da psiquiatria novecentista (Foucault, 2001; 2006), foi fundamental para que os especialistas médicos convocassem o Estado a operar conforme as normas higiênicas, interferindo nos hábitos urbanos em nome do afastamento das moléstias.

A crença no aspecto social das enfermidades também, segundo o historiador, poderia ser usada para explicar a ascendência do saber médico/higienista sobre o universo escolar. O modelo higienista adotado pelos clínicos brasileiros levava-os a definir

um amplo programa de regras para o funcionamento dos colégios, compreendendo a localização e a arquitetura dos edifícios escolares, organização da rotina, das práticas e hábitos que deveriam ser desenvolvidos junto aos alunos, alimentação, exercícios corporais, cuidados com as excreções, de modo a conservar e desenvolver as faculdades física, intelectuais e afetivas ou morais dos alunos. (Gondra, 2004, p. 165)

Nos tempos descritos por Gondra, a medicina explicava as afecções dos cidadãos a partir do modelo anatômico. Em razão dessa opção, os clínicos dedicaram-se a descrever os males corpóreos por meio da afetação que eles provocavam nos órgãos corporais. Seguindo essa linha argumentativa, justifica-se a preocupação dos médicos brasileiros quanto aos hábitos dos escolares. Dita apreensão guardava a pretensão de criar corpos resistentes que suportassem as agressões provenientes do meio insalubre. Além disso, o projeto higienista continha um substrato moral, uma vez que considerava estreita a relação entre civilidade e asseio.

$\mathrm{Na}$ análise de Gondra, o saber médico, em busca de legitimidade política e social, teria produzido um conjunto de representações - tanto acerca do papel da medicina quanto da própria população - que teria redundado na produção de uma matriz médica para a escola moderna. A partir daí, segundo o autor, "tudo aquilo que pudesse ser considerado da natureza humana deveria ser transformado em objeto de planejamento e intervenção racionais" (Gondra, 2004, p. 485).

Tendo em mente a proposição de Gondra, poder-se-ia sugerir que o encontro da medicina com a educação escolar descreveria uma relação escorada no projeto higienista de "colocar sob domínio da medicina não apenas os corpos dos indivíduos, mas também as águas, os ares e os lugares” (Gondra, 2004, p. 483). Tratar-se-ia, assim, de uma relação assimétrica de um saber que se generalizaria para o conjunto da

\begin{tabular}{|l|l|l|l|l|}
\hline Qovista Oialectus & Ano 4 & n. 11 & Agosto - Dezembro 2017 & p. $127-144$ \\
\hline
\end{tabular}


sociedade, estabelecendo-se como um poder capaz de intervir em condutas, modificar significados e instituir modos de vida.

A partir da concepção de Gondra, é possível aventar que a escola moderna no Brasil, já nos seus primórdios, consistiu em um espaço para a instalação de um discurso que submeteu os corpos dos alunos a significados exteriores a eles e, por conseguinte, abrigou em suas práticas procedimentos que instituíram seus hábitos em prol de uma sociabilidade programada pelos cânones científicos. Referida concepção talvez represente uma interpretação possível para aquilo que Foucault sugeriu como “estatização do biológico" (Foucault, 2005, p. 286).

Contudo, retomando a própria aula de 17 de março de 1976, fica claro que o tipo de relação de poder alcançado pela racionalização biológica da vida inverte a lógica que presidia o poder soberano. Previamente à era disciplinar, segundo Foucault, os monarcas aplicavam o direito de espada sobre a vida dos súditos; portanto, a sobrevivência dos indivíduos era tida como uma concessão do soberano. Uma relação de poder nitidamente assimétrica, portanto.

Na mão contrária, o exercício do poder estatal, no momento de medicalização da sociedade, já não estava mais alicerçado na palavra do soberano. Os Estados pósnapoleônicos haviam convertido os súditos em cidadãos e, portanto, tratavam seus governados como sujeitos de direitos. Dessa forma, o poder baseado nos discursos biológicos ter-se-ia instalado em uma sociedade na qual os indivíduos já se consideravam livres, não mais tomando os ditames estatais como ordenações impostas arbitrariamente.

Claro está que, em muitos campos, o Estado pós-napoleônico manteve seu caráter de soberania. Todavia, à luz das observações foucaultianas, a biologia das populações implicava uma prática radicalmente nova no século XIX. E sua novidade provinha exatamente do fato de ela gerir as condições de vida dos populares sob a ótica de seres livres, geneticamente constituídos, medicamente corrigíveis e biologicamente aprimoráveis.

Seguindo esse raciocínio, não caberia, portanto, considerar o exercício do poder médico sobre a população de escolares como uma ação de mera dominação. Tal acepção torna-se ainda mais evidente quando se analisa o momento que sucede à escolarização descrito por Gondra.

\begin{tabular}{|l|l|l|l|l|}
\hline Qovista Oialectus & Ano 4 & n. 11 & Agosto - Dezembro 2017 & p. $127-144$ \\
\hline
\end{tabular}


Significativa parte dos historiadores da educação brasileira considera que o momento da Escola Nova no Brasil possui características semelhantes àquelas descritas por Gondra. Segundo tais estudiosos, estabeleceram-se, na primeira metade do século XX brasileiro, práticas educacionais alavancadas por saberes médicos que ressignificaram os hábitos dos populares à luz das representações higienistas, racionalistas, burguesas, racistas etc. (Rago, 1985; Herschmann, 1996; Lobo, 1997; Patto, 1999; Monarcha, 1999; Mate, 2002; Rocha, 2003; Gondra, 2004; Carvalho, 2006; D’avila, 2006).

Na quase totalidade dos trabalhos acadêmicos devotados ao período, guardadas as especificidades de seus objetos e análises, a escola moderna desponta como tributária de um amplo programa ideológico dedicado a desviar os cidadãos e, mais especificamente, os escolares de uma suposta origem livre, igualitária e autêntica.

Margareth Rago (1985) estudou os embates entre os agentes estatais e o movimento anarquista na São Paulo dos anos 1890 a 1930. Para tanto, compilou enunciados produzidos por médicos, políticos e cientistas dedicados a implantar, nos primórdios da industrialização paulista, programas voltados à higienização da cidade, ao disciplinamento dos operários e à moralização das famílias pobres. A perspectiva adotada pela pesquisadora considerou que os referidos programas visavam a práticas segundo as quais "a tentativa de domesticação do operariado passa pela construção de um modelo de comportamento e de vida, que se tenta impor aos dominados" (Rago, 1985, p. 12). Imposição, aplicação de modelos exógenos e sobredeterminação ideológica foram critérios utilizados pela autora para sopesar acerca das ações estatais dirigidas à nascente classe operária paulistana. Por meio de regulamentos fabris, teorizações eugênicas e ressignificações de papeis sociais, os agentes da burguesia teriam, segundo Rago, exercido um poder indiscriminado, calando o operariado em germe.

Tal como Gondra, Rago visualiza a discursividade médica como ação assimétrica sobre as práticas cotidianas da população explorada. Ao fazê-lo, exacerba a hipótese da dominação e da manipulação de classes. No entanto, tal perspectiva finda por desprezar algo que estaria fermentando nos corpos daqueles que resistiam ao autoritarismo higienista: a crença na condução racional da própria vida.

Desse modo, ao descrever o operário como um personagem em essência oposto ao burguês, a autora, parece-nos, deixa escapar aquilo que mais profundamente se

\begin{tabular}{|l|l|l|l|l|}
\hline Gonista Dialectus & Ano 4 & n. 11 & Agosto - Dezembro 2017 & p. $127-144$ \\
\hline
\end{tabular}


produz quando se embatem dominantes e dominados, no contexto da luta pela hegemonia dos discursos sobre a vida, ou seja, a dita crença na possibilidade de se conhecer e, no mesmo golpe, controlar a vida por meio de um planejamento de tipo científico. Tal afã racionalista, regulador e cientificista expressa-se na asserção da própria autora quando descreve a criança segundo os planos de uma educação anarquista, como um ser que "possui aptidões naturais positivas que as práticas pedagógicas devem ajudar a desenvolver” (Rago, 1985, p. 149). Isso porque, para os anarquistas, "qualquer mudança radical dependeria do esforço pessoal de cada um no sentido de sua auto-emancipação e aí caberia um papel fundamental à educação enquanto formadora do homem novo" (Rago, 1985, p. 154). Ou seja, na visão de Rago acerca do choque entre burguesia e proletariado, a verdade do primeiro somente vence porque é autoritária e violenta, enquanto à segunda - racional e libertária - caberia o trabalho da resistência.

Como se pode atestar, a perspectiva que estabelece aquilo que Foucault enunciou como "estatização do biológico" (Foucault, 2005, p. 286) em termos do circuito imposição/resistência/controle, finda por ter bastante guarida no pensamento pedagógico acima anunciado.

Para Micael Herschmann (1996), por sua vez, tal circuito corporificou-se no momento de instalação do positivismo no Brasil, particularmente na intersecção dos campos literário e médico. Segundo o autor, desde os anos finais do século XIX até a década de 1930, vicejaram enunciados que postulavam a conexão da ciência com o ideário moderno. Assim, os positivistas teriam associado insalubridade a ignorância e, por conseguinte, definido a escola como lugar para estabelecer uma "ideologia de classes" (Herschmann, 1996, p. 64), segundo a qual os modelos e as representações desenvolvidas pelo campo médico ter-se-iam convertido em "normas, leis, enfim, práticas que visavam promover a fiscalização e o controle social" (Herschmann, 1996, p. 64). Dessa maneira, o Estado firmava-se como âmbito de imposição da representação positivista cujo ideário contemplava um projeto de regeneração do povo pela via da educação. Aos populares, restaria o cotidiano no qual eles resistiriam a tal projeto, criando sua "própria nação dentro da nação moderna” (Herschmann, 1996, p. 67).

Do mesmo modo que Rago vislumbrou a resistência dos dominados em uma racionalidade paralela, Herschmann a encontrou no nacionalismo. Ademais, incontinenti, ambos autores detectaram, nas práticas de resistência às investidas estatais,

\begin{tabular}{|l|l|l|l|l|}
\hline Gonista Dialectus & Ano 4 & n. 11 & Agosto - Dezembro 2017 & p. $127-144$ \\
\hline
\end{tabular}


inflexões para o controle social que analisaram. Assim fazendo, os dois, ao inserirem razão e nação no campo da resistência dos populares, afastaram-se das considerações foucaultianas acerca da biopolítica, uma vez que, para o pensador francês, foi exatamente por meio da cientifização da vida que o Estado moderno pôde incorporar o discurso nacionalista e constituir os mecanismos de aprimoramento das raças nacionais, a partir da exclusão daqueles comportamentos que enfraqueciam a vitalidade da população. Ou seja, na perspectiva foucaultiana a díade nação/razão constituiu as bases para o estabelecimento do Estado biológico e, por conseguinte, racista.

Também Cecília Hanna Mate (2002) focalizou o processo de racionalização da educação implantado pelo Estado brasileiro nas décadas de 1920 e 1930. Centrando suas análises nas reformas do ensino realizadas nos anos 1920, respectivamente, em São Paulo, no Ceará e no Distrito Federal, a autora discorreu sobre o minucioso controle operado pelas instituições inauguradas pelo movimento reformista. Desde as ações de recenseamento da população escolarizável até a aplicação de testes psicológicos, a educação moderna foi descrita pela autora como um grande programa - centralizado e hegemônico - voltado à instrução e ao disciplinamento dos contingentes escolares.

O caráter centralizador e regulamentador do Estado, no qual Hanna Mate apoiou seus argumentos, faz coro com uma visão segundo a qual as práticas de controle social sustentadas pelo disciplinamento dos saberes redundariam na produção de corpos estudantis dóceis e úteis para desfrute do sistema industrial capitalista.

Em um diapasão não imediatamente foucaultiano, outros pesquisadores do campo educacional dedicaram-se igualmente a tematizar o escolanovismo. Quando tais autores atribuem à Escola Nova o papel de "reserva ideológica sempre disponível e em favor da hegemonia burguesa" (Vale, 2009, p. 42), não abdicam de associar a figura de Lourenço Filho à de um "patologista social” (Nunes, 1998, p.109), responsável por desviar a potência libertária inerente ao higienismo mental em prol da ação impositiva do Estado (Garcia, 2006). Desse modo, conforme tais estudiosos, o escolanovismo teria abandonado sua origem democrática em troca de um "revival de teorias psicológicas" (Campos e Shiroma, 1999, p. 491).

Referidas teorias teriam induzido os alunos a um "desenvolvimento intelectual abstrato" (Kuhlmann Jr., 2000, p.17), desviando-os da realidade vivida pelas classes populares nas quais eles estavam inseridos. Nessa direção, a elucidação das artimanhas do poder estaria a serviço de uma utópica noção de democracia, de acordo com a qual a

\begin{tabular}{|l|l|l|l|l|}
\hline Gonista Dialectus & Ano 4 & n. 11 & Agosto - Dezembro 2017 & p. $127-144$ \\
\hline
\end{tabular}


natureza liberta e benevolente das crianças (Mogilka, 2003) seria preservada e potencializada em direção a um futuro pacífico e produtivo.

O mesmo otimismo foi observado nos textos dedicados a louvar o pretenso caráter terapêutico da Escola Nova. Este teria associado educação a cuidado (Fazenda e Souza, 2012) e, por conseguinte, permitido aos alunos exercitar uma pedagogia do si mesmo (Teles e Cerqueira, 2013), com o fito de despertar a subjetividade supostamente inerente a todos os humanos (Moura e Silva, 2009).

A realização do ser-aluno como humano também foi alvo dos enunciados pedagógicos que se dedicaram a problematizar o papel da psicologia no interior das práticas escolanovistas. Nesse sentido, destacou-se recorrentemente a ascendência de John Dewey como pensador-referência na proposta de uma educação de fato renovada, porque humanizadora e democrática. O caminho para tal humanização teria sido apontado conforme a sequência conscientização-socialização-inteligência. Assim, atribuindo a Dewey as máximas segundo as quais educar é socializar (Cunha, 1996) e educar é humanizar (Santos, 2000), os autores dedicados ao escolanovismo consideram que a escola moderna deveria exercitar uma razão socialmente construída no sentido de conscientizar os alunos em relação à sua responsabilidade no compartilhamento com a coletividade, sempre em busca de uma sociedade harmônica, pacífica e eficiente.

Por fim, avulta um prisma argumentativo que se dirige àquilo que se convencionou intitular higienismo, no intuito de definir os procedimentos instalados pela matriz discursiva médica na escola. Referido conceito é tido por alguns autores como apropriado para sugerir que a interferência da medicina nas coordenadas escolares operou por via da imposição de representações sobre o corpo dos estudantes, de modo a torná-los suscetíveis à vida econômica que os envolvia (Richter e Fernandes, 2010). Enunciando tal operação em termos de captura da infância pela ordem médica (Gondra, 2010), ditos autores analisaram a medicina higiênica em termos de inculcação de hábitos, de modo a garantir a disciplina e, por conseguinte, proceder ao espraiamento da medicalização na escola e na sociedade (Rocha, 2011).

\section{Por uma apreensão outra da díade biopolítica-educação}

Uma perspectiva de análise lastreada pela teorização foucaultiana, que se dedicasse a compreender as relações entre biopolítica e educação para além do viés da imposição, da ressignificação ou do mero disciplinamento dos estudantes, seria

\begin{tabular}{|l|l|l|l|l|}
\hline Gonista Dialectus & Ano 4 & n. 11 & Agosto - Dezembro 2017 & p. $127-144$ \\
\hline
\end{tabular}


necessariamente solidária, a nosso ver, aos estudos levados a cabo nos últimos cursos do pensador (Foucault, 2010; 2010a; 2011; 2014; 2016).

Visando prospectar as relações entre experiência e verdade como o horizonte no interior do qual ter-se-iam estabelecido os processos de subjetivação no Ocidente desde os gregos, Foucault optou por se afastar daquilo que se conhece como história das mentalidades. Para tanto, recusou buscar representações produzidas pelos indivíduos em seus embates com alguma suposta realidade. Tal enfoque representacional, segundo o autor, levaria à crença no desnível entre discurso e realidade, ou ainda entre conhecimento e consciência, confinando os indivíduos à condição de meros alvos da dominação. Referida perspectiva historiográfica, além de desprezar a postura ativa de cada qual dos personagens históricos frente aos saberes, também os confinaria na posição de elementos submissos a discursos que os definiriam exteriormente.

Assim, fazer da análise um método para o desvelamento de representações que teriam sido produzidas por saberes dominantes e impostas aos dominados com a intenção de os desviar do sentido real de suas experiências, seria manter o modus operandi argumentativo que reduziu a história das relações entre saúde e educação à concepção segundo a qual a escola teria sido apenas uma das instituições na qual o higienismo de matriz médica se instalou, obstaculizando práticas potencialmente libertadoras. Segundo tal ideário, a tarefa do intelectual educacional seria revelar os erros do passado e, por conseguinte, emancipar os sujeitos da educação presente, rumo a uma superação dos entraves de uma liberdade ontológica ofuscada pelos descaminhos da história. Nada mais antagônico ao legado de Foucault.

Ademais, se tal operação fosse possível, as teorizações foucaultianas acerca da emergência do poder de normalização anteriormente sinalizadas por nós deveriam ser abandonadas, uma vez que, em diversas passagens, o autor francês asseverou que as relações de poder - sobretudo a partir do advento da noção de biopolítica e, depois, a de governamentalidade - dependem inteiramente da resposta ativa daqueles que constituem seu alvo. Trocando em miúdos, o saber pedagógico moderno nunca dispensou a liberdade, nem deixou de reformular a si mesmo a partir das saturações operadas pelos indivíduos sobre os quais ele incide.

De nossa parte, sustentamos a hipótese de que a liberdade do educando proposta pelo escolanovismo se converteu no principal fundamento em que se apoiaram as propostas de irradiação dos mecanismos de segurança em uma sociedade urbano-

\begin{tabular}{|l|l|l|l|l|}
\hline Qevista Dialectus & Ano 4 & n. 11 & Agosto - Dezembro 2017 & p. $127-144$ \\
\hline
\end{tabular}


industrial nascente, como aquela dos anos 1920-30 no Brasil, cujos ecos parecem persistir na atualidade educacional.

Claro está que a escolarização moderna possui um renitente condão disciplinar, tal como descrito pelos autores aqui recenseados. No entanto, a crítica operada pelos estudos foucaultianos na educação poderia, em nosso entendimento, alcançar estratos mais intrincados e, quiçá, mais inusitados, caso se dedicasse a perspectivar os efeitos gerados pela produtividade, em termos de processos biopolíticos, operados pelo escolanovismo e seus tantos desdobramentos históricos.

Caso as análises ultrapassassem o binarismo poder/resistência, elas alcançariam o cerne dos processos de veridicção/subjetivação que levam os indivíduos modernos a se conceberem como seres em permanente desenvolvimento, em busca de constantes segurança e autocontrole perante um mundo de infinitos estímulos para corpos tidos como limitados, mas plenamente adaptáveis.

No bojo de tais processos, inclui-se o perene e inexorável advento da patologização das dificuldades escolares, constituído pari passu à proliferação das investigações dirigidas à ciência da cognição. Nesse campo discursivo, o cérebro converteu-se no espaço em que todas as potencialidades e limitações individuais se manifestariam. Portanto, segundo essa lógica, o desenvolvimento neurológico seria um dado da natureza, e, por conseguinte, sua estimulação permanente redundaria no constante aprimoramento pessoal. Destarte, ao condicionar desenvolvimento biológico a estratégias de autogoverno, as práticas educacionais contemporâneas estariam produzindo seres que se subjetivariam a partir da crença de estarem em permanente déficit diante daquilo que sua natureza biológica permitiria.

Eis aqui um novo horizonte problemático que se descortina à pesquisa educacional.

\section{REFERÊNCIAS:}

CAMPOS, Roselane Fátima; SHIROMA, Eneida Oto. O resgate da Escola Nova pelas reformas educacionais contemporâneas. Revistas Brasileira de Estudos Pedagógicos, Brasília, v. 80, n. 196, p. 483-493, set./dez. 1999.

CARVALHO, Marta Maria Chagas de. Quando a história da educação é a história da disciplina e da higienização das pessoas. In: FREITAS, Marcos Cezar de (Org.). História social da infância no Brasil. São Paulo: Cortez, 2006. p. 291-310.

\begin{tabular}{|l|l|l|l|l|}
\hline Gonista Dialectus & Ano 4 & n. 11 & Agosto - Dezembro 2017 & p. $127-144$ \\
\hline
\end{tabular}


CUNHA, Marcus Vinicius da. Dewey e Piaget no Brasil dos anos trinta. Cadernos de Pesquisa, São Paulo, n. 97, p. 5-12, mai. 1996.

D’AVILA, Jerry. Diploma de brancura: política social e racial no Brasil. 1917-1945. São Paulo: Editora UNESP, 2006.

FAZENDA, Ivani Catarina Arantes; SOUZA, Fernando César de. Diálogos interdisciplinares em saúde e educação: a arte de cuidar. Educação \& Realidade, Porto Alegre, v. 37, n. 1, p. 107-124, jan./abr. 2012.

FOUCAULT, Michel. Vigiar e punir: história da violência nas prisões. Petrópolis: Vozes, 1987.

Os anormais: curso dado no Collège de France (1974 - 1975). São Paulo: Martins Fontes, 2001.

Em defesa da sociedade: curso dado no Collège de France (1974 - 1975). São Paulo: Martins Fontes, 2005.

O poder psiquiátrico: curso dado no Collège de France (1973-1974). São Paulo: Martins Fontes, 2006.

A hermenêutica do sujeito: curso dado no Collège de France (1981-1982). São Paulo: WMF Martins Fontes, 2010.

. O governo de si e dos outros: curso dado no Collège de France (1982-1983).

São Paulo: WMF Martins Fontes, 2010a.

A coragem da verdade: curso no Collège de France (1983-1984). São Paulo: WMF Martins Fontes, 2011.

Do governo dos vivos: curso no Collège de France (1979-1980). São Paulo: WMF Martins Fontes, 2014.

Subjetividade e verdade: curso no Collège de France (1980-1981). São Paulo: WMF Martins Fontes, 2016.

GARCIA, Ronaldo Aurélio Gimenes. Educação e psicanálise: a criança problema na perspectiva de análise da obra de Arthur Ramos (Rio de Janeiro 1930-1940). Praxis Educativa, Ponta Grossa, v. 1, n. 2, p. 65-76, jul./dez. 2006.

GONDRA, José Gonçalves. Artes de civilizar: medicina, higiene e educação escolar na corte imperial. Rio de Janeiro: Editora UERJ, 2004.

GONDRA, José Gonçalves. A emergência da infância. Educação em Revista, Belo Horizonte, v. 26, n. 1, p. 195-214, abr. 2010.

HERSCHMANN, Micael. Entre a insalubridade e a ignorância: a construção do campo médico no Brasil. In: HERSCHMANN, Micael; KROPF, Simone; NUNES, Clarice.

\begin{tabular}{|l|l|l|l|l|}
\hline Qovista Dialectus & Ano 4 & n. 11 & Agosto - Dezembro 2017 & p. $127-144$ \\
\hline
\end{tabular}


Missionários do progresso: médicos, engenheiros e educadores no Rio de Janeiro 18701937. Rio de Janeiro: Diadorim, 1996.

KUHLMANN JR., Moisés. Histórias da educação infantil brasileira. Revista Brasileira de Educação, Rio de Janeiro, n. 14, p. 5-18, maio/jun./jul./ago. 2000.

LOBO, Lilian Ferreira. Os infames da história: a instituição das deficiências no Brasil. Tese (Doutorado) - Pontifícia Universidade Católica, Rio de Janeiro, 1997.

MATE, Cecília Hanna. Tempos modernos na escola: os anos 30 e a racionalidade da educação brasileira. Bauru: EDUSC, 2002.

MOGILKA, Maurício. Educar para a democracia. Cadernos de Pesquisa, São Paulo, n. 119, p. 129-146, jul. 2003.

MONARCHA, Carlos. Escola normal da praça: o lado noturno das luzes. Campinas: Editora da UNICAMP, 1999.

MOURA, Francisco; SILVA, Talitha Elen. A educação clínica como metodologia pedagógica: investigação sobre a aplicação da psicanálise na área educacional em Minas Gerais. Educação em Revista, Belo Horizonte, v. 25, n. 1, p. 265-291, jan. 2009.

NUNES, Clarice. Historiografia comparada da escola nova: algumas questões. Revista da Faculdade de Educação, São Paulo, v. 19, n. 1, p. 105-125, jan./jun. 1998.

PATTO, Maria Helena de Souza. A produção do fracasso escolar. São Paulo: Casa do Psicólogo, 1999.

RAGO, Luzia Margareth. Do cabaré ao lar: a utopia da cidade disciplinar. Brasil (1890-1930). Rio de Janeiro: Paz e Terra, 1985.

RICHTER, Ana Cristina; VAZ, Alexandre Fernandes. Educar e cuidar do corpo: biopolítica no atendimento à pequena infância. Educação em Revista, Belo Horizonte, v. 29, n. 4, p. 117-134, ago. 2010.

ROCHA, Heloisa Pimenta. A higienização dos costumes: educação escolar e saúde no projeto do Instituto de Hygiene de São Paulo (1918-1925). Campinas: Mercado de Letras, 2003.

Alfabetização, saneamento e regeneração nas iniciativas de difusão da escola primária em São Paulo. Pro-Posições, Campinas, v. 22, n. 2(65), p. 151-172, maio/ago. 2011.

SANTOS, Heloísa Occhiuzedos. Ideário pedagógico municipalista de Anísio Teixeira. Cadernos de Pesquisa, São Paulo, n. 10, p. 105-124, jul. 2000.

TELES, Ana Maria Orofino; CERQUEIRA, Teresa Cristina Siqueira. A pedagogia do si mesmo: debate sobre a emergência do sujeito que aprende. Educação \& Realidade, Porto Alegre, v. 38, n. 3, p. 931-951, jul./set. 2013

\begin{tabular}{|l|l|l|l|l|}
\hline Qovista Dialectus & Ano 4 & n. 11 & Agosto - Dezembro 2017 & p. $127-144$ \\
\hline
\end{tabular}


VALE, Antonio Marques do. Abordagem sobre um tema complexo de história: a relação entre finalidades da educação, poder e interesses. Praxis Educativa, Ponta Grossa, v. 4, n. 1, p. 41-50, jan./jun. 2009.

\begin{tabular}{|l|l|l|l|l|}
\hline Q Ponista Dialectus & Ano 4 & n. 11 & Agosto - Dezembro 2017 & p. $127-144$ \\
\hline
\end{tabular}

